\title{
1 Instrument Description
}

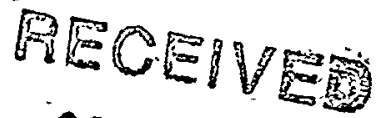

\subsection{Overview}

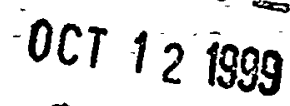

POW3 provides rapid data collection while maintaining reasonaby gbo resolution. Figure 1 provides a schematic representation of POW3, and Table 1 gives the parameters for this instrument. This is a workhorse refinement instrument for structures of modest complexity. In addition, this instrument views a cold moderator to enable long-wavelength neutrons to be used to measure long d-spacings.

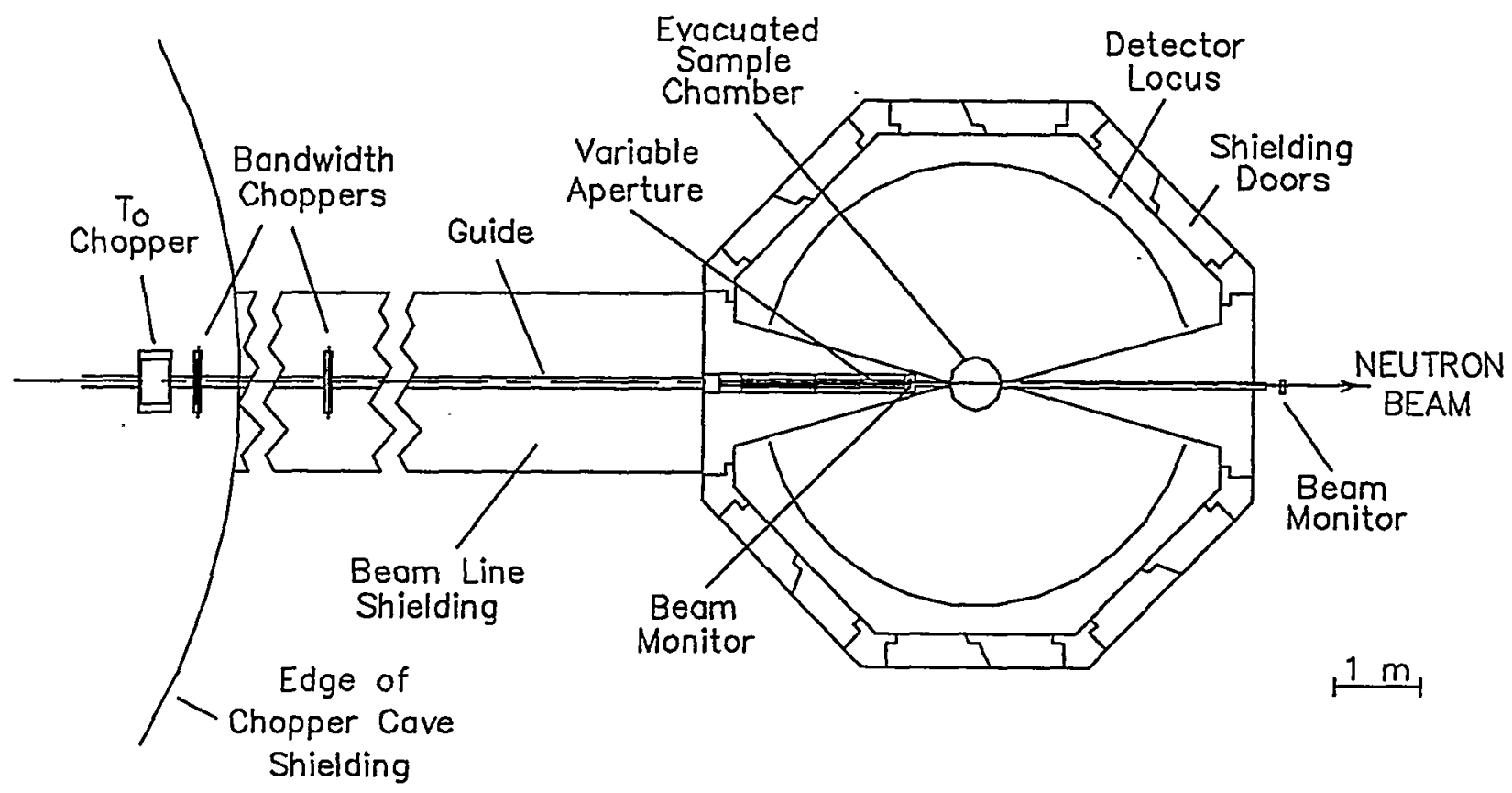

Fig. 1. Schematic plan view of the workhorse powder diffractometer POW3.

Work supported in part by the U. S. Department of Energy, BES, contract No. W-31-109-ENG38. 


\section{DISCLAIMER}

This report was prepared as an account of work sponsored by an agency of the United States Government. Neither the United States Government nor any agency thereof, nor any of their employees, make any warranty, express or implied, or assumes any legal liability or responsibility for the accuracy, completeness, or usefulness of any information, apparatus, product, or process disclosed, or represents that its use would not infringe privately owned rights. Reference herein to any specific commercial product, process, or service by trade name, trademark, manufacturer, or otherwise does not necessarily constitute or imply its endorsement, recommendation, or favoring by the United States Government or any agency thereof. The views and opinions of authors expressed herein do not necessarily state or reflect those of the United States Government or any agency thereof. 


\section{DISCLAIMER}

Portions of this document may be illegible in electronic image products. Images are produced from the best available original document. 
ES-1.1.8.2-6001-RE-A-00

Table 1. Parameters for the powder diffractometer POW3

\begin{tabular}{|c|c|c|}
\hline Component & Parameter & Value \\
\hline Moderator & $\begin{array}{l}\text { Beam line } \\
\text { Moderator }\end{array}$ & $\begin{array}{l}2 \mathrm{TU} \\
\text { Liquid-H2, decoup. Pois }\end{array}$ \\
\hline Geometry & $\begin{array}{l}\text { Source-sample distance } \\
\text { Sample-detector distance }\end{array}$ & $\begin{array}{l}30.0 \mathrm{~m} \\
2.5 \mathrm{~m}\end{array}$ \\
\hline $\mathrm{T}_{0}$ chopper & $\begin{array}{l}\text { Type } \\
\text { Radius to beam center } \\
\text { Length } \\
\text { Distance from moderator } \\
\text { Frequency } \\
\text { Beam width at chopper } \\
\text { Wavelength range to open or close }\end{array}$ & $\begin{array}{l}\text { Horizontal-axis } T_{0} \\
250 \mathrm{~mm} \\
300 \mathrm{~mm} \\
7.0 \mathrm{~m} \\
30 \mathrm{~Hz} \\
15 \mathrm{~mm} \\
0.18 \AA @ 30 \mathrm{~Hz}\end{array}$ \\
\hline Bandwidth chopper \#1 & $\begin{array}{l}\text { Type } \\
\text { Radius to beam center } \\
\text { Length } \\
\text { Distance from moderator } \\
\text { Frequency } \\
\text { Beam width at chopper } \\
\text { Wavelength range to open or close }\end{array}$ & $\begin{array}{l}\text { Disk } \\
250 \mathrm{~mm} \\
10 \mathrm{~mm} \\
7.5 \mathrm{~m} \\
15 \text { to } 60 \mathrm{~Hz} \\
15 \mathrm{~mm} \\
0.08 \AA @ 60 \mathrm{~Hz}\end{array}$ \\
\hline Bandwidth chopper \#2 & $\begin{array}{l}\text { Type } \\
\text { Radius to beam center } \\
\text { Length } \\
\text { Distance from moderator } \\
\text { Frequency } \\
\text { Beam width at chopper } \\
\text { Wavelength range to open or close }\end{array}$ & $\begin{array}{l}\text { Disk } \\
250 \mathrm{~mm} \\
10 \mathrm{~mm} \\
12.0 \mathrm{~m} \\
15 \text { to } 60 \mathrm{~Hz} \\
15 \mathrm{~mm} \\
0.05 \AA @ 60 \mathrm{~Hz}\end{array}$ \\
\hline Guide & $\begin{array}{l}\text { Type } \\
\text { Coating, sides } \\
\text { Coating, top and bottom } \\
\text { Channel width } \\
\text { Channel height } \\
\text { Moderator-to-guide distance } \\
\text { Moderator to end of guide sides } \\
\text { Moderator to end of guide top and bottom } \\
\text { Filling }\end{array}$ & $\begin{array}{l}\text { Straight } \\
\text { Natural Ni } \\
3 \times \theta_{\mathrm{c}} \text { supermirror } \\
15 \mathrm{~mm} \\
60 \mathrm{~mm} \\
8.0 \mathrm{~m} \\
26.0 \mathrm{~m} \\
29.0 \mathrm{~m} \\
\text { evacuated to }<10^{-2} \text { torr }\end{array}$ \\
\hline Collimation & Near sample & Variable aperture \\
\hline Beam-line shielding & $\begin{array}{l}\text { Steel radial thickness around beam } \\
\text { Paraffin radial thickness around steel } \\
\text { Channel for guide } \\
\text { Length }\end{array}$ & $\begin{array}{l}0.7 \mathrm{~m} \\
0.2 \mathrm{~m} \\
0.2 \mathrm{~m} \times 0.2 \mathrm{~m} \\
19 \mathrm{~m}\end{array}$ \\
\hline
\end{tabular}


Table 6.3-1 (continued)

\begin{tabular}{|c|c|c|}
\hline Component & Parameter & Value \\
\hline Beam stop & $\begin{array}{l}\text { Steel } \\
\text { Paraffin radial thickness around steel } \\
\text { Re-entrant hole in steel }\end{array}$ & $\begin{array}{l}1.6 \mathrm{~m} \times 1.6 \mathrm{~m} \times 2.6 \mathrm{~m} \\
0.2 \mathrm{~m} \\
0.2 \mathrm{~m} \times 0.2 \mathrm{~m} \times 0.5 \mathrm{~m}\end{array}$ \\
\hline Sample & $\begin{array}{l}\text { Width (maximum beam size) } \\
\text { Height (maximum beam size) }\end{array}$ & $\begin{array}{l}10 \mathrm{~mm} \\
50 \mathrm{~mm}\end{array}$ \\
\hline Detector angular coverage & & $\sim 15^{\circ}$ to $165^{\circ}$ \\
\hline Standard detectors & $\begin{array}{l}\text { Type } \\
\text { Diameter } \\
\text { Length } \\
\text { Distance from sample } \\
\text { Number } \\
\text { Solid angle coverage }\end{array}$ & $\begin{array}{l}{ }^{3} \mathrm{He} \text { proportional } \\
12 \mathrm{~mm} \\
380 \mathrm{~mm} \\
2.5 \mathrm{~m} \\
500 \\
0.36 \mathrm{sr}\end{array}$ \\
\hline $\begin{array}{l}\text { Linear position sensitive } \\
\text { detectors }\end{array}$ & $\begin{array}{l}\text { Type } \\
\text { Diameter } \\
\text { Encoded length } \\
\text { Position resolution } \\
\text { Distance from sample } \\
\text { Number } \\
\text { Solid angle coverage }\end{array}$ & $\begin{array}{l}{ }^{3} \mathrm{He} \text { proportional } \\
12 \mathrm{~mm} \\
380 \mathrm{~mm} \\
25 \mathrm{~mm} \\
2.5 \mathrm{~m} \\
300 \\
0.22 \mathrm{sr}\end{array}$ \\
\hline Data acquisition & & Standard system \\
\hline Scattering chamber & $\begin{array}{l}\text { Geometry } \\
\text { Diameter, excluding shielding } \\
\text { Height, excluding shielding } \\
\text { Filling, direct beam portion } \\
\text { Filling, remainder } \\
\text { Shielding, top and bottom } \\
\text { Shielding, sides } \\
\text { Shielding thickness and composition }\end{array}$ & $\begin{array}{l}\text { Vertical axis cylinder } \\
5.2 \mathrm{~m} \\
0.5 \mathrm{~m} \\
\text { evacuated to }<10^{-2} \text { torr } \\
\text { Helium } \\
\text { Fixed } \\
\text { Removable } \\
\text { TBD }\end{array}$ \\
\hline Sample chamber & $\begin{array}{l}\text { Depth } \\
\text { Diameter } \\
\text { Filling }\end{array}$ & $\begin{array}{l}\sim 1.2 \mathrm{~m} \\
\sim 0.6 \mathrm{~m} \\
\text { Evacuated to } 10^{-6} \text { torr }\end{array}$ \\
\hline Resolution & $\begin{array}{l}\delta \mathrm{d} / \mathrm{d}, \text { backscattering } \\
\delta \mathrm{d} / \mathrm{d}, 90^{\circ} \text { scattering } \\
\end{array}$ & $\begin{array}{l}1.3 \times 10^{-3} \text { fwhm } \\
2.4 \times 10^{-3} \text { fwhm }\end{array}$ \\
\hline
\end{tabular}




\subsection{Source}

A poisoned decoupled supercritical hydrogen moderator at $\sim 22 \mathrm{~K}$ provides a polychromatic beam of cold neutrons to the instrument. The design documented here assumes a fwhm pulse width of $\delta t \approx 58 \mu$ s at $10 \AA, \delta t \approx 48 \mu$ s at $5 \AA, \delta t \approx 35 \mu$ s at $3 \AA$, and $\delta t \approx 11 \mu$ s at $1 \AA .{ }^{1}$ This moderator was selected for POW3 because one of the functions of POW3 is to look at long dspacing samples. For this application the cold moderator is necessary to provide sufficient longwavelength neutrons and the poisoning provides better resolution with these cold neutrons. This moderator is still quite intense for the shorter wavelengths $(0.5-5 \AA)$ and with the poisoning has quite sharp pulses over all this range.

Beamline 2TU was chosen for this instrument because this beamline views the poisoned cold TU moderator normal to its surface, thus providing the best possible timing resolution for the instrument.

\subsection{Choppers}

A $T_{0}$ chopper is used to cut out the prompt pulse to reduce background, and a series of bandwidth-limiting choppers is required to limit the incident bandwidth to prevent frame overlap, the condition in which fast neutrons from one pulse catch up with slow neutrons from the preceding pulse. To provide maximum flexibility, this series of choppers must be able to select different bandwidths as well as vary the wavelength at which the incident bandwidth is centered. The requirement to vary the selected bandwidth can be satisfied by using two choppers. This bandwidth can be centered at any wavelength simply by adjusting the phase of the bandwidth choppers. The second chopper, when properly positioned, can also help to cut out additional neutrons that could contaminate the data, as discussed below.

Preliminary optimization of the chopper locations and speeds was done using a spreadsheet to evaluate the wavelengths for which the chopper system is fully open and the wavelengths for which one or more of the choppers is opening or closing. Table 2 shows the parameters assumed for the choppers, and Tables $3 \mathrm{a}$ and $3 \mathrm{~b}$ show the opening and closing times and wavelengths for each of these choppers for several different choices of chopper phases. Appendix A gives the equations used for these calculations.

Figure 2 shows a time-distance diagram for POW3 based on the data in Tables 2-3 for several different choices of chopper phasing. It is evident that for some of these phasing choices the second bandwidth chopper is needed to block unwanted wavelengths (e.g., neutrons from the wrong pulse) that can pass through the first chopper. One such example is shown in Fig. 2f. Such time-distance diagrams have been used to arrive at useful, if not yet fully optimized, positions for the two bandwidth choppers and the $T_{0}$ chopper. Note that Fig. $2 f$ shows that at this stage of the optimization the position of the $\mathrm{T}_{0}$ chopper is not yet appropriate for operating in frame 5 . 
Table 2. Assumed chopper parameters for POW3.

\begin{tabular}{|l|r|}
\hline source frequency $(\mathrm{Hz})$ & 60.00 \\
\hline $\mathrm{T}_{0}$ chopper diameter $(\mathrm{mm})$ & 500.00 \\
\hline $\mathrm{T}_{0}$ chopper distance $\left.(\mathrm{m})\right)^{*}$ & 7.00 \\
\hline beam width at $\mathrm{T}_{0}$ chopper $(\mathrm{mm})$ & 15.00 \\
\hline bandwidth chopper \#1 diameter $(\mathrm{mm})$ & 500.00 \\
\hline bandwidth chopper \#1 distance $(\mathrm{m})^{*}$ & 7.50 \\
\hline beam width at bandwidth chopper \#1 (mm) & 15.00 \\
\hline bandwidth chopper \#2 diameter $(\mathrm{mm})$ & 500.00 \\
\hline bandwidth chopper \#2 distance $(\mathrm{m})^{*}$ & 12.00 \\
\hline beam width at bandwidth chopper \#2 (mm) & 15.00 \\
\hline distance to detectors $(\mathrm{m})$ & 32.50 \\
\hline
\end{tabular}

* Distances are measured from the moderator along the neutron path. 

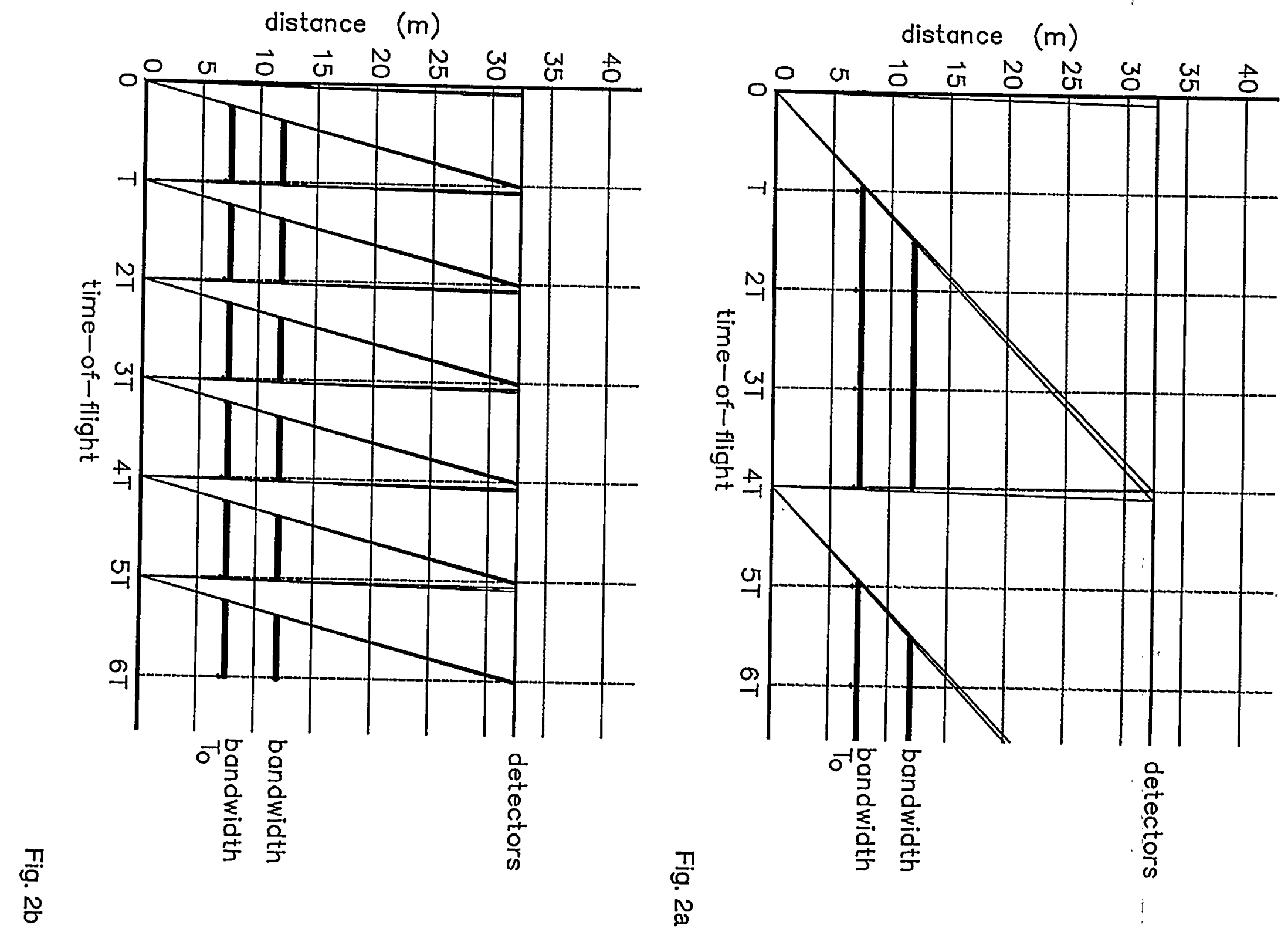

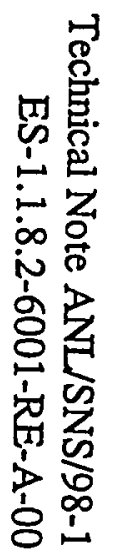




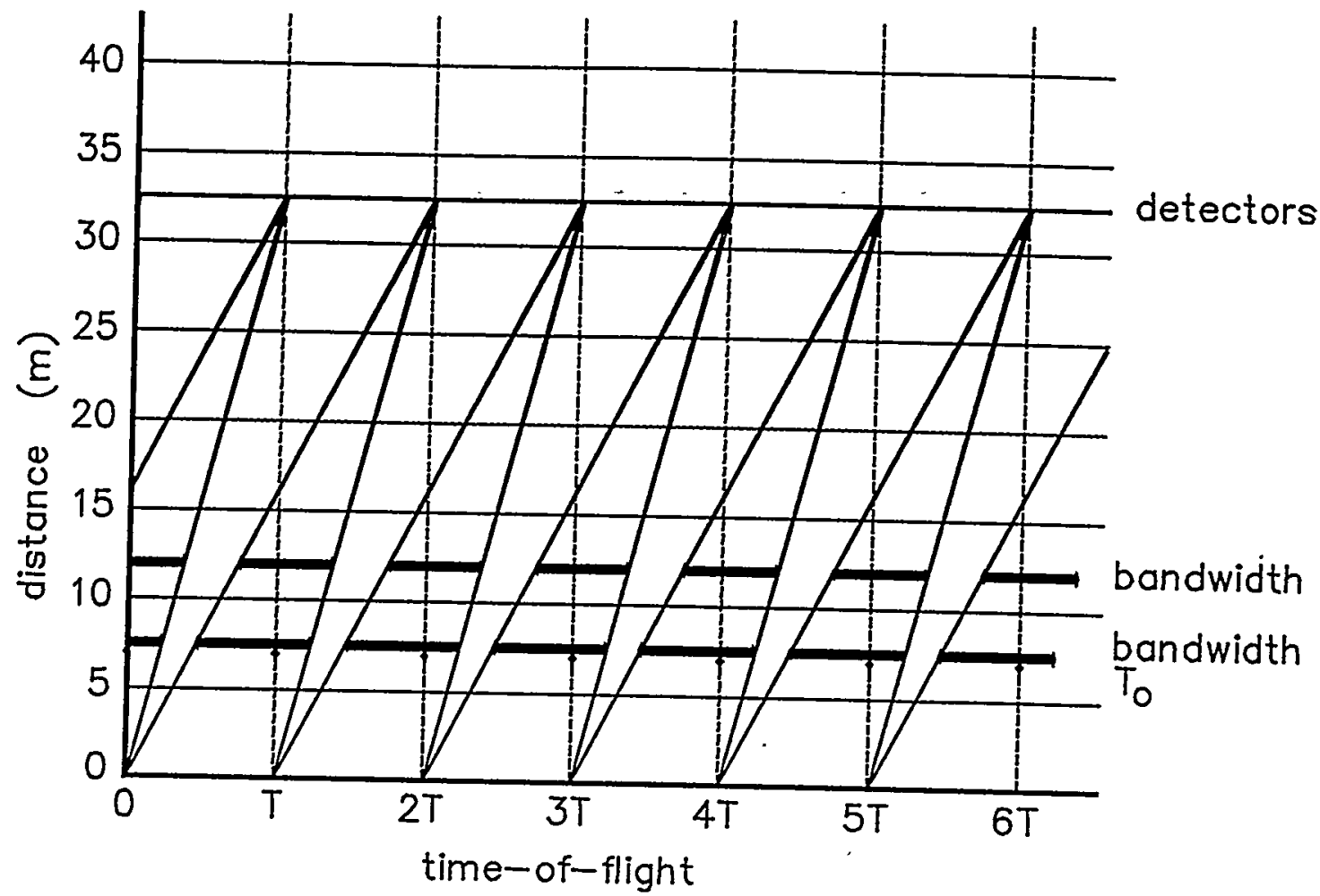

Fig. 2c

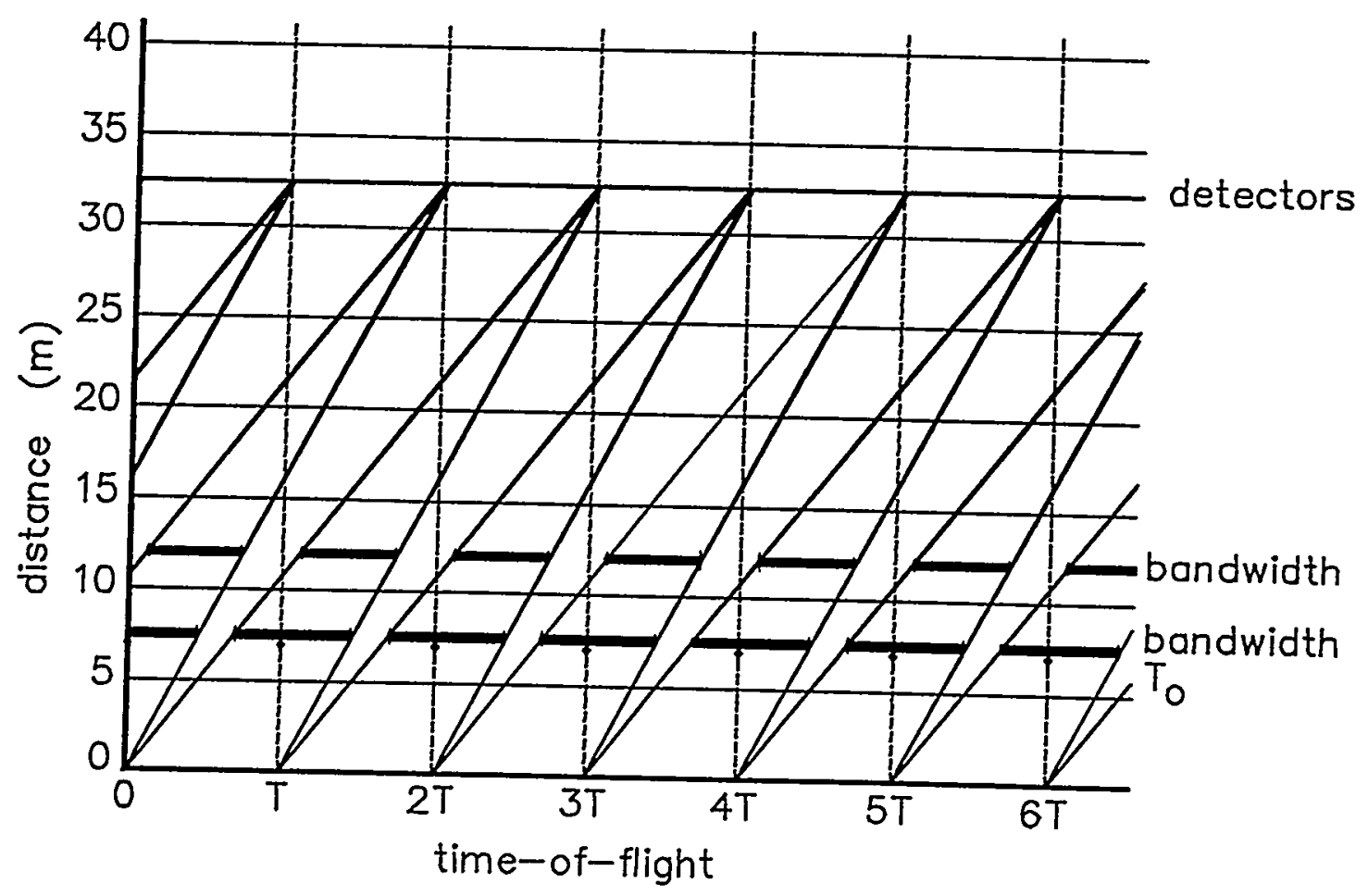

Fig. 2d 
ES-1.1.8.2-6001-RE-A-00

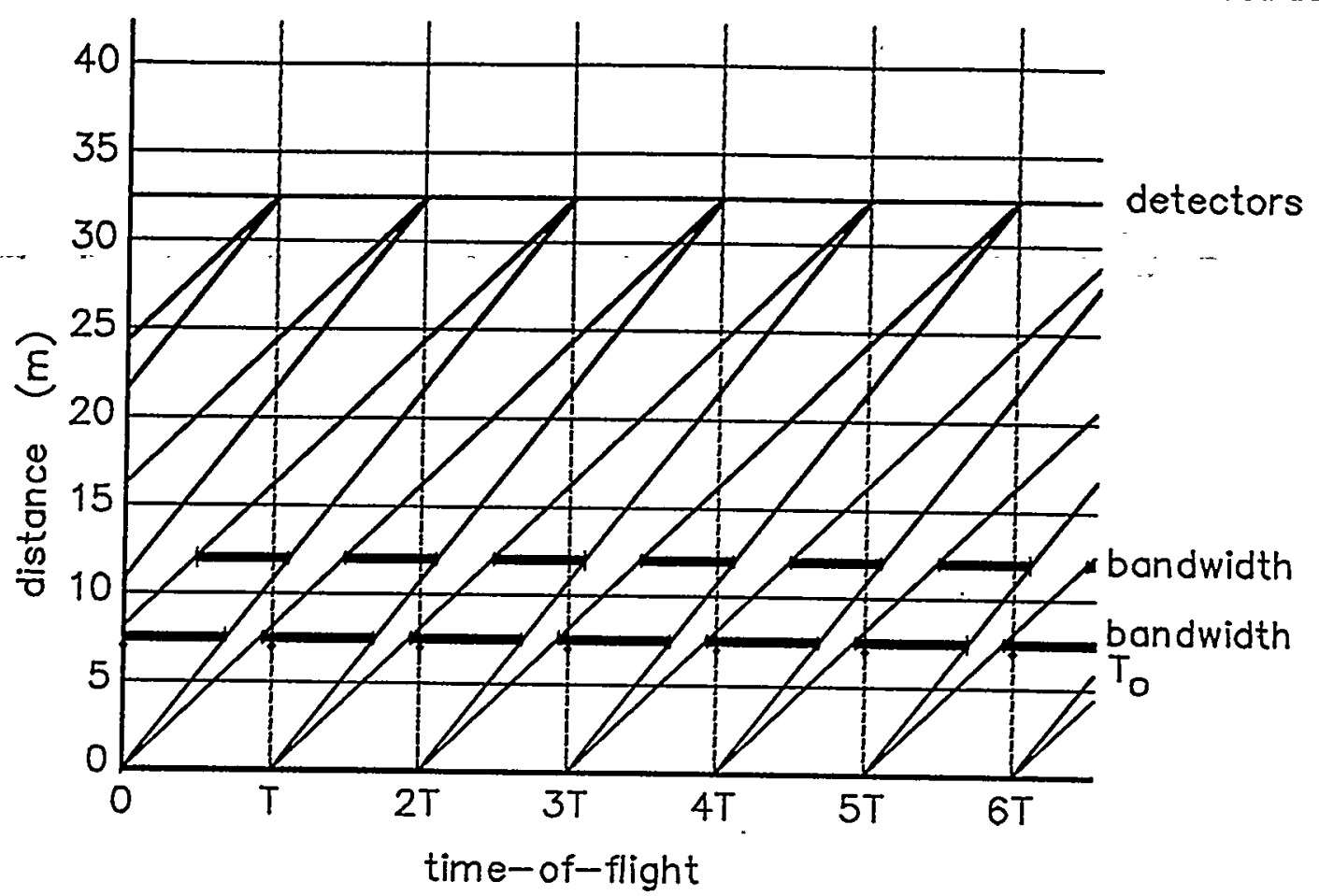

Fig. $2 e$



Fig. $2 f$

Figure 2. Timing diagram for POW3. a) frames 1-4. (0.18 to 8.11 $\AA$ ); b) frame 1. (0.18 to $2.03 \AA)$; c) frame 2 . $(2.08$ to $4.06 \AA)$; d) frame 3. (4.11 to $6.09 \AA)$; e) frame 4. (6.14 to 8.11 $\AA$ ); ) frame 5. (8.17 to $10.14 \AA)$. Heavy dashed horizontal lines indicate the chopper-closed periods. In all cases the bandwidth lines indicate the boundaries of both the fully-open and fully-closed chopper conditions. 
Technical Note ANL/SNS/98-1

ES-1.1.8.2-6001-RE-A-00

Table 3a. Opening and closing times for different chopper settings for POW3.*

\begin{tabular}{|c|c|c|c|c|c|c|c|c|c|c|c|c|}
\hline Frame $\mathrm{N}$ & 1 & 2 & 3 & 4 & 5 & 6 & $1-2$ & $1-3$ & $1-4$ & $1-5$ & $1-6$ & $4-6$ \\
\hline$t_{\max -N)}(\mu s)$ & 16667 & 33333 & 50000 & 66667 & 83333 & 100000 & 33333 & 50000 & 66667 & 83333 & 100000 & 100000 \\
\hline $\mathrm{T}_{0} \mathrm{f}_{\mathrm{TO}}(\mathrm{Hz})$ & 30.0 & 30.0 & 30.0 & 30.0 & 30.0 & 30.0 & 30.0 & 30.0 & 30.0 & 30.0 & 30.0 & 30.0 \\
\hline $\mathrm{T}_{0} \Delta \mathrm{t}_{\mathrm{TO}}(\mu \mathrm{s})$ & 318 & 318 & 318 & 318 & 318 & 318 & 318 & 318 & 318 & 318 & 318 & 318 \\
\hline & & & & & & & & & & & & \\
\hline $\mathrm{BW} 1 \mathrm{f}_{\mathrm{BW}}(\mathrm{Hz})$ & 60.0 & 60.0 & 60.0 & 60.0 & 60.0 & 60.0 & 30.0 & 20.0 & 15.0 & 12.0 & 10.0 & 20.0 \\
\hline $\mathrm{BW} 1 \Delta \mathrm{t}_{\mathrm{BW}}(\mu \mathrm{s})$ & 159 & 159 & 159 & 159 & 159 & 159 & 318 & 477 & 637 & 796 & 955 & 477 \\
\hline BW2 $f_{\mathrm{Ban}}(\mathrm{Hz})$ & 600 & 600 & 600 & 600 & 600 & 600 & 200 & 200 & 150 & 10 & 100 & 90 \\
\hline $\mathrm{BW} 2 \Delta \mathrm{t}_{\mathrm{BW} 2}(\mu \mathrm{s})$ & 159 & 159 & 159 & 159 & 159 & 159 & 318 & 477 & 637 & $\frac{12.0}{796}$ & 955 & $\frac{20.0}{477}$ \\
\hline & & & & & & & & & & & & \\
\hline$t_{\min -(N)}(\mu s)$ & 1478 & 17098 & 33764 & 50431 & 67098 & 83764 & 1478 & 1478 & 1478 & 1478 & 1478 & 51293 \\
\hline & & & & & & & & & & & & \\
\hline$T_{0} t_{c-(M)}(\mu s)$ & 0 & 16667 & 33333 & 50000 & 66667 & 83333 & & & & & & \\
\hline$T_{0} t_{c o-N}(\mu \mathrm{s})$ & 318 & 16985 & 33652 & 50318 & 66985 & 83652 & & & & & & \\
\hline$T_{0} t_{s c-m}(\mu s)$ & 16348 & 33015 & 49682 & 66348 & 83015 & & & & & & $T$ & \\
\hline & & & & & & & & & & & & \\
\hline $\mathrm{BW} 1 \mathrm{t}_{\mathrm{s}-\mathrm{m}}(\mathrm{N})(\mu \mathrm{s})$ & 182 & 3786 & 7633 & 11479 & 15325 & 19171 & 23 & -136 & -296 & -455 & -614 & 11359 \\
\hline BW1 $t_{00-(N)}(\mu s)$ & 341 & 3946 & 7792 & 11638 & 15484 & 19330 & 341 & 341 & 341 & 341 & 341 & 11837 \\
\hline$B W 1 t_{s c-p)}(\mu s)$ & 3846 & 7692 & 11538 & 15385 & 19231 & 23077 & 7692 & 11538 & 15385 & 19231 & 23077 & 23077 \\
\hline BW1 tear $(\mu s)$ & 4005 & 7851 & 11698 & 15544 & 19390 & 23236 & 8011 & 12016 & 16021 & 20027 & 24032 & 23554 \\
\hline$B W 2 t_{s 0-N)}(\mu s)$ & 387 & 6154 & 12300 & $1016 ?$ & 2015 & 20760 & 227 & 68 & 01 & IE & 100 & \\
\hline $\mathrm{BW} 2 \mathrm{t}_{\mathrm{co-} \mathrm{N}}(\mu \mathrm{s})$ & 546 & 6313 & 12467 & 18621 & 24775 & $\frac{30705}{30028}$ & $\frac{221}{546}$ & 50 & $\frac{-91}{-512}$ & $\frac{-250}{515}$ & $\frac{-409}{54}$ & 18462 \\
\hline $\mathrm{BW} 2 \mathrm{t}_{\mathrm{sc}-\mathrm{N})}(\mu \mathrm{s})$ & 6154 & 12308 & 18462 & 24615 & 30769 & 36923 & 12308 & 18462 & 24615 & $\frac{140}{30760}$ & $\frac{340}{36023}$ & $\frac{205092}{160025}$ \\
\hline $\mathrm{BW} 2 \mathrm{t}_{\mathrm{ec}(\mathrm{N})}(\mu \mathrm{s})$ & 6313 & 12467 & 18621 & 24775 & 30928 & 37082 & 12626 & 18939 & 25252 & 31565 & $\frac{50923}{37878}$ & $\frac{20925}{37401}$ \\
\hline
\end{tabular}

T0 $=$ t-zero chopper, BW1 = first bandwidth chopper, BW2 = second bandwidth chopper

$\mathrm{f}=$ frequency, $\Delta \mathrm{t}=$ time for chopper edge to sweep thru beam

so = start open; $c o=$ end open; $c=$ fully closed; $s c=$ start closc; $c c=$ end close

This table assumes $\Delta \mathrm{t}_{\mathrm{cl}}=0$ for the $\mathrm{T}_{0}$ chopper.

* See Appendix A for definitions and cquations. 
Technical Note ANL/SNS/98-1

ES-1.1.8.2-6001-RE-A-00

Table 3b. Accessible wavelengths for different chopper settings for POW3. *

\begin{tabular}{|c|c|c|c|c|c|c|c|c|c|c|c|c|}
\hline Frame $N$ & 1 & 2 & 3 & 4 & 5 & 6 & $1-2$ & $1-3$ & $1-4$ & $1-5$ & $1-6$ & $4-6$ \\
\hline$t_{\max -(N)}(\mu s)$ & 16667 & 33333 & 50000 & 66667 & 83333 & 100000 & 33333 & 50000 & 66667 & 83333 & 100000 & 100000 \\
\hline $\mathrm{T}_{0} \mathrm{f}_{\mathrm{TO}}(\mathrm{Hz})$ & 30.0 & 30.0 & 30.0 & 30.0 & 30.0 & 30.0 & 30.0 & 30.0 & 30.0 & 30.0 & 30.0 & 30.0 \\
\hline $\mathrm{T}_{0} \Delta \lambda_{\mathrm{T}_{0}}(\AA)$ & 0.18 & 0.18 & 0.18 & 0.18 & 0.18 & 0.18 & 0.18 & 0.18 & 0.18 & 0.18 & 0.18 & 0.18 \\
\hline $\mathrm{BW} 1 \mathrm{f}_{\mathrm{BW} 1}(\mathrm{~Hz})$ & 60.0 & 60.0 & 60.0 & 60.0 & 60.0 & 60.0 & 30.0 & 20.0 & 15.0 & 12.0 & 10.0 & 20.0 \\
\hline $\mathrm{BW} 1 \Delta \lambda_{\mathrm{BW1}}(\AA)$ & 0.08 & 0.08 & 0.08 & 0.08 & 0.08 & 0.08 & 0.17 & 0.25 & 0.34 & 0.42 & 0.50 & 0.25 \\
\hline & & & & & & & & & & & & \\
\hline $\mathrm{BW} 2 \mathrm{f}_{\mathrm{BW} 2}(\mathrm{~Hz})$ & 60.0 & 60.0 & 60.0 & 60.0 & 60.0 & 60.0 & 30.0 & 20.0 & 15.0 & 12.0 & 10.0 & 20.0 \\
\hline $\mathrm{BW} 2 \Delta \lambda_{\mathrm{BW} 2}(\AA)$ & 0.05 & 0.05 & 0.05 & 0.05 & 0.05 & 0.05 & 0.10 & 0.16 & 0.21 & 0.26 & 0.31 & 0.16 \\
\hline$\lambda_{\text {inc-max-(N) }}(\AA)$ & 2.03 & 4.06 & 6.09 & 8.11 & 10.14 & 12.17 & 4.06 & 6.09 & 8.11 & 10.14 & 12.17 & 12.17 \\
\hline$\lambda_{\text {inc-min-(N) }}(\AA)$ & 0.18 & 2.08 & 4.11 & 6.14 & 8.17 & 10.19 & 0.18 & 0.18 & 0.18 & 0.18 & 0.18 & 6.24 \\
\hline & & & & & & & & & & & & \\
\hline $\mathrm{T}_{0} \lambda_{c-(N)}(\AA)$ & 0.00 & 9.42 & 18.84 & 28.25 & 37.67 & 47.09 & & & & & & \\
\hline$T_{0} \lambda_{\text {eo- } N)}(\AA)$ & 0.18 & 9.60 & 19.02 & 28.43 & 37.85 & 47.27 & & & & & & \\
\hline $\mathrm{T}_{0} \lambda_{\mathrm{se}-\mathbb{N})}(\AA)$ & 9.24 & 18.66 & 28.07 & 37.49 & 46.91 & & & & & & & \\
\hline $\mathrm{BW} 1 \lambda_{\mathrm{so} \cdot(\mathrm{N})}(\AA)$ & 0.10 & 2.00 & 4.03 & 6.05 & 8.08 & 10.11 & 0.01 & -0.07 & -0.16 & -0.24 & -0.32 & 5.99 \\
\hline BW1 $\lambda_{\text {ea } \cdot(\mathrm{M})}(\AA)$ & 0.18 & 2.08 & 4.11 & 6.14 & 8.17 & 10.19 & 0.18 & 0.18 & 0.18 & 0.18 & 0.18 & 6.24 \\
\hline BW1 $\lambda_{s c-(N)}(\AA)$ & 2.03 & 4.06 & 6.09 & 8.11 & 10.14 & 12.17 & 4.06 & 6.09 & 8.11 & 10.14 & 12.17 & 12.17 \\
\hline $\mathrm{BW} 1 \lambda_{\mathrm{ec}-\mathrm{M})}(\AA)$ & 2.11 & 4.14 & 6.17 & 8.20 & 10.23 & 12.25 & 4.22 & 6.34 & 8.45 & 10.56 & 12.67 & 12.42 \\
\hline $\mathrm{BW} 2 \lambda_{\mathrm{SO} . \mathrm{N}}(\AA)$ & 0.13 & 2.03 & 4.06 & 6.09 & 8.11 & 10.14 & 0.07 & 0.02 & -0.03 & -0.08 & -0.13 & 6.09 \\
\hline $\mathrm{BW} 2 \lambda_{\mathrm{eo}-(\mathrm{N})}(\AA)$ & 0.18 & 2.08 & 4.11 & 6.14 & 8.17 & 10.19 & 0.18 & 0.18 & 0.18 & 0.18 & 0.18 & 6.24 \\
\hline$B W 2 \lambda_{s c-(N)}(\AA)$ & 2.03 & 4.06 & 6.09 & 8.11 & 10.14 & 12.17 & 4.06 & 6.09 & 8.11 & 10.14 & 12.17 & 12.17 \\
\hline$B W 2 \lambda_{e c-(N)}(\AA)$ & 2.08 & 4.11 & 6.14 & 8.17 & 10.19 & 12.22 & 4.16 & 6.24 & 8.32 & 10.40 & 12.49 & 12.33 \\
\hline
\end{tabular}

$\mathrm{T} 0=\mathrm{t}$-zcro chopper, $\mathrm{BW} 1=$ first bandwidth chopper, $\mathrm{BW} 2=$ second bandwidth chopper

$\mathrm{f}=$ frequency, $\Delta \lambda=$ wavelength change during sweep of chopper edge thru beam

so = start open; $e o=$ end open; $c=$ fully closed; $s c=$ start close; $e c=$ end close

This table assumes $\Delta t_{c l}=0$ for the $T_{0}$ chopper.

* See Appendix A for definitions and equations. 
ES-1.1.8.2-6001-RE-A-00

\subsection{Guide}

\subsubsection{Guide Gain}

The intensity on the sample is given by the intensity with no guide multiplied by the gain from the guide. Appendix B provides the equations used to estimate guide gain. These were used to establish the preliminary set of guide parameters shown in Table 4 for POW3. The gains calculated using these parameters with the guide starting $2.5 \mathrm{~m}$ from the moderator and $8 \mathrm{~m}$ from the moderator are shown respectively in Tables $5 \mathrm{a}$ and $5 \mathrm{~b}$.

The neutron guide system for POW3 was designed to meet the constraint that the incident beam divergence must be no worse than that from natural collimation (i.e., horizontal collimation given by the ratio of the moderator size to the incident path length). This may not have been the optimum constraint for such a diffractometer, as it is very conservative, but it illustrates the principles involved.

The collimation constraint imposed here means that the horizontal gain of the guide can be at most unity. Under these conditions the intensity at the sample is independent of the guide width, provided the guide width and incident and exit path lengths satisfy the requirements for full illumination given in Appendix B. The width of the guide for POW3 was chosen to satisfy these requirements with physically reasonable values for $\mathrm{L}_{\text {inc }}$ and $\mathrm{L}_{\text {exit. }}$. Parameters for the vertical guide were chosen to give a physically reasonable guide size with reasonable values for $L_{\text {inc }}$ and $L_{\text {exit. }}$ Even for these constraints the guide is not yet fully optimized. Further optimization or optimization with different constraints would result in different guide parameters, so the constraints must be carefully considered.

The main advantage of the horizontal guide in this case is that it allows a much narrower beam to be used than would otherwise have been the case. This improves the characteristics of the $T_{0}$ and bandwidth choppers, and also results in a lower background of fast neutrons. It may also permit the splitting off of a second guide to operate more than one instrument from this beam port. 
Table 4. Preliminary guide parameters for POW3.

\begin{tabular}{|c|c|c|}
\hline Parameter & Meaning & Value \\
\hline $\mathrm{M}_{\mathrm{h}}$ & moderator width $(\mathrm{mm})$ & 100.00 \\
\hline $\mathrm{M}_{\mathrm{v}}$ & moderator height (mm) & 120.00 \\
\hline $\mathrm{L}_{\mathrm{inc}}$ & moderator-guide distance $(\mathrm{m})$ & $\begin{array}{l}2.50 \\
8.00 \\
\end{array}$ \\
\hline $\mathrm{g}_{\mathrm{h}}$ & guide width (mm) & 15.00 \\
\hline$g_{v}$ & guide height (mm) & 60.00 \\
\hline $\mathrm{m}_{\mathrm{h}}$ & horizontal supermirror " $\mathrm{m}$ " & 1.00 \\
\hline$m_{v}$ & vertical supermirror "m" & 3.00 \\
\hline$\lambda^{*}$ & characteristic wavelength (Angstroms) & straight \\
\hline$\underline{R}$ & radius of curvature $(\mathrm{m})$ & straight \\
\hline$L_{\text {sight }}$ & line-of sight distance (m) & straight \\
\hline $\mathrm{L}$ & source-sample distance $(\mathrm{m})$ & 30.00 \\
\hline$L_{\text {exith }}$ & horizontal guide-sample distance (m) & 4.00 \\
\hline$L_{\text {exit-v }}$ & vertical guide-sample distance (m) & 1.00 \\
\hline$S_{h}$ & sample width (mm) & 10.00 \\
\hline $\mathrm{S}_{\mathrm{v}}$ & sample height (mm) & 50.00 \\
\hline $\mathrm{M}_{\mathrm{h}} / \mathrm{L}$ & no-guide collimation horizontal (rad) & 0.00333 \\
\hline $\mathrm{M}_{\mathrm{v}} / \mathrm{L}$ & no-guide collimation vertical (rad) & 0.00400 \\
\hline $\mathrm{g}_{\mathrm{h}} / \mathrm{L}_{\mathrm{exit-h}}$ & exit collimation horizontal (rad) & 0.00375 \\
\hline$g_{v} / L_{\text {exit-v }}$ & exit collimation vertical (rad) & 0.06000 \\
\hline & $(\mathrm{M}-\mathrm{g}) / 2$ (horizontal) $(\mathrm{mm})$ & 42.50 \\
\hline & $(\mathrm{M}+\mathrm{g}) / 2$ (horizontal) $(\mathrm{mm})$ & 57.50 \\
\hline & $(\mathrm{M}-\mathrm{g}) / 2$ (vertical) $(\mathrm{mm})$ & 30.00 \\
\hline & $(\mathrm{M}+\mathrm{g}) / 2$ (vertical) $(\mathrm{mm})$ & 90.00 \\
\hline & $(\mathrm{g}-\mathrm{S}) / 2$ (horizontal) (mm) & 2.50 \\
\hline & $(\mathrm{g}+\mathrm{S}) / 2$ (horizontal) $(\mathrm{mm})$ & 12.50 \\
\hline & $(\mathrm{g}-\mathrm{S}) / 2($ vertical $)(\mathrm{mm})$ & 5.00 \\
\hline & $(\mathrm{g}+\mathrm{S}) / 2$ (vertical) $(\mathrm{mm})$ & 55.00 \\
\hline
\end{tabular}


Technical Note ANL/SNS/98-1

ES-1.1.8.2-6001-RE-A-00

Table 5a. Approximate guide gains for POW3 $\left(\mathrm{L}_{\mathrm{lnc}}=2.5 \mathrm{~m}\right)$.

\begin{tabular}{|c|c|c|c|c|c|c|c|c|c|c|c|}
\hline$\lambda$ & 0.5 & 1 & 2 & 3 & 4 & 5 & 6 & 7 & 8 & 9 & 10 \\
\hline $2 \theta_{\mathrm{cess}-\mathrm{h}}(\mathrm{rad})$ & 0.00170 & 0.00340 & 0.00680 & 0.01020 & 0.01360 & 0.01700 & 0.02040 & 0.02380 & 0.02720 & 0.03060 & 0.03400 \\
\hline $2 \theta_{c-e-\pi, v}(\mathrm{rad})$ & 0.00510 & 0.01020 & 0.02040 & 0.03060 & 0.04080 & 0.05100 & 0.06120 & 0.07140 & 0.08160 & 0.09180 & 0.10200 \\
\hline$L_{\text {imc-full-h }}(\mathrm{m})$ & 50.00 & 25.00 & 12.50 & 8.33 & 6.25 & 5.00 & 4.17 & 3.57 & 3.13 & 2.78 & 2.50 \\
\hline$L_{\text {incofull-v }}(m)$ & 11.76 & 5.88 & 2.94 & 1.96 & 1.47 & 1.18 & 0.98 & 0.84 & 0.74 & 0.65 & 0.59 \\
\hline$\frac{F_{\text {inch }}}{n}$ & 1.00 & 1.00 & 1.00 & 1.00 & 1.00 & 1.00 & 1.00 & 1.00 & 1.00 & 1.00 & 1.00 \\
\hline$\frac{F_{\text {inc-v }}}{n}$ & 1.00 & 1.00 & 1.00 & 0.99 & 0.93 & 0.85 & 0.76 & 0.67 & 0.59 & 0.52 & 0.47 \\
\hline$\frac{F_{\text {exith }}}{n-n_{1}}$ & 0.99 & 0.86 & 0.55 & 0.37 & 0.28 & 0.22 & 0.18 & 0.16 & 0.14 & 0.12 & 0.11 \\
\hline$F_{\text {exit-v }}$ & 1.00 & 1.00 & 0.97 & 0.93 & 0.90 & 0.87 & 0.86 & 0.85 & 0.85 & 0.85 & 0.85 \\
\hline$G_{\text {ideal-h }}$ & 0.51 & 1.02 & 2.04 & 3.06 & 4.08 & 5.10 & 6.12 & 7.14 & 8.16 & 9.18 & 10.20 \\
\hline$G_{\text {ideal.vv }}$ & 1.28 & 2.55 & 5.10 & 7.65 & 10.20 & 12.75 & 15.30 & 17.85 & 20.40 & 22.95 & 25.50 \\
\hline$G_{\text {actual-h }}$ & 0.50 & 0.88 & 1.13 & 1.13 & 1.13 & 1.13 & 1.13 & 1.13 & 1.13 & 1.13 & 1.13 \\
\hline$G_{\text {actual. } v}$ & 1.28 & 2.55 & 4.96 & 7.03 & 8.49 & 9.46 & 10.00 & 10.19 & 10.20 & 10.20 & 10.20 \\
\hline$\frac{G_{\text {ideal }}}{n}$ & 0.65 & 2.60 & 10.40 & 23.41 & 41.62 & 65.03 & 93.64 & 127.45 & 166.46 & 210.68 & 260.10 \\
\hline $\mathrm{G}_{\text {actual }}$ & 0.64 & 2.25 & 5.59 & 7.91 & 9.56 & 10.64 & 11.26 & 11.47 & 11.47 & 11.47 & 11.47 \\
\hline
\end{tabular}

Table 5b. Approximate guide gains for POW3 $\left(\mathrm{L}_{\mathrm{lnc}}=8.0 \mathrm{~m}\right)$.

\begin{tabular}{|c|c|c|c|c|c|c|c|c|c|c|c|}
\hline$\lambda$ & 0.5 & 1 & 2 & 3 & 4 & 5 & 6 & 7 & 8 & 9 & 10 \\
\hline $2 \theta_{c \cdot e r \cdot h}(\mathrm{rad})$ & 0.00170 & 0.00340 & 0.00680 & 0.01020 & 0.01360 & 0.01700 & 0.02040 & 0.02380 & 0.02720 & 0.03060 & 0.03400 \\
\hline $2 \theta_{\text {ceefrov }}(\mathrm{rad})$ & 0.00510 & 0.01020 & 0.02040 & 0.03060 & 0.04080 & 0.05100 & 0.06120 & 0.07140 & 0.08160 & 0.09180 & 0.10200 \\
\hline $\mathrm{L}_{\text {ine-full-h }}(\mathrm{m})$ & 50.00 & 25.00 & 12.50 & 8.33 & 6.25 & 5.00 & 4.17 & 3.57 & 3.13 & 2.78 & 2.50 \\
\hline $\mathrm{L}_{\text {inc-full. } \mathrm{y}}(\mathrm{m})$ & 11.76 & 5.88 & 2.94 & 1.96 & 1.47 & 1.18 & 0.98 & 0.84 & 0.74 & 0.65 & 0.59 \\
\hline$F_{\text {inch }}$ & 1.00 & 1.00 & 1.00 & 1.00 & 0.91 & 0.74 & 0.61 & 0.53 & 0.46 & 0.41 & 0.37 \\
\hline$F_{\text {inc:v }}$ & 1.00 & 0.98 & 0.73 & 0.49 & 0.37 & 0.29 & 0.25 & 0.21 & 0.18 & 0.16 & 0.15 \\
\hline$F_{\text {exilth }}$ & 0.99 & 0.86 & 0.55 & 0.37 & 0.30 & 0.30 & 0.30 & 0.30 & 0.30 & 0.30 & 0.30 \\
\hline$F_{\text {exil-v }}$ & 1.00 & 1.00 & 0.99 & 0.99 & 0.99 & 0.99 & 0.99 & 0.99 & 0.99 & 0.99 & 0.99 \\
\hline$G_{\text {ideal-h }}$ & 0.51 & 1.02 & 2.04 & 3.06 & 4.08 & 5.10 & 6.12 & 7.14 & 8.16 & 9.18 & 10.20 \\
\hline$G_{\text {ideal-v }}$ & 1.28 & 2.55 & 5.10 & 7.65 & 10.20 & 12.75 & 15.30 & 17.85 & 20.40 & 22.95 & 25.50 \\
\hline$G_{\text {actual-h }}$ & 0.50 & 0.88 & 1.13 & 1.13 & 1.13 & 1.13 & 1.13 & 1.13 & 1.13 & 1.13 & 1.13 \\
\hline$G_{\text {actual.v }}$ & 1.28 & 2.49 & 3.68 & 3.72 & 3.72 & 3.72 & 3.72 & 3.72 & 3.72 & 3.72 & 3.72 \\
\hline$G_{\text {ideal }}$ & 0.65 & 2.60 & 10.40 & 23.41 & 41.62 & 65.03 & 93.64 & 127.45 & 166.46 & 210.68 & 260.10 \\
\hline$G_{\text {actual }}$ & 0.64 & 2.19 & 4.14 & 4.18 & 4.18 & 4.18 & 4.18 & 4.18 & 4.18 & 4.18 & 4.18 \\
\hline
\end{tabular}




\subsubsection{Guide Curvature}

This guide is not curved.

\subsubsection{Monte Carlo Simulations}

Monte Carlo simulations were used to obtain a more accurate estimate of the performance of the POW3 guide system. Parameters were the same as in Tables 1 and 4 except as noted. For the simulations, neutrons were assumed to be emitted with equal probability from the entire moderator surface, and with equal probability within the angular range \pm 0.06 radians about the nominal beam direction. Since the critical angle for natural Ni at $10 \AA$ is only 0.017 radians, this range of angular divergence was more than enough to include all neutrons that could be accepted by the POW3 guides. The same number of randomly generated initial neutron paths $(1,000,000)$ was used for each 1-dimensional simulation, and total guide performance was obtained by comparing neutrons on sample with and without the guide for the corresponding simulations for the horizontal and vertical direction. For these simulations, the guides were assumed to have reflectivity of 1.0 up to the critical angle $\theta_{c}$ for natural $\mathrm{Ni}$, and a reflectivity of 0.95 from $\theta_{c}$ to $\mathrm{m} \theta_{c}$, where $\mathrm{m}$ takes on the appropriate supermirror value for the particular set of guide surfaces. Table 6 shows the results of these simulations.

Table 6a. Simulated guide gains for POW3 $\left(\mathrm{L}_{\mathrm{inc}}=2.5 \mathrm{~m}\right.$ with $0.4 \mathrm{~m}$ gap).

\begin{tabular}{|l|c|c|c|c|}
\hline$\lambda$ & 1 & 3 & 6 & 10 \\
\hline $\mathrm{G}_{\text {actual-h }}$ & 0.86 & 0.97 & 0.98 & 1.00 \\
\hline $\mathrm{G}_{\text {actual-v }}$ & 2.38 & 5.48 & 6.77 & 7.32 \\
\hline $\mathrm{G}_{\text {actual }}$ & 2.03 & 5.31 & 6.60 & 7.31 \\
\hline
\end{tabular}

Table 6b. Simulated guide gains for POW3 ( $L_{j \mathrm{jc}}=2.5 \mathrm{~m}$ with no gap).

\begin{tabular}{|l|c|c|c|c|}
\hline$\lambda$ & 1 & 3 & 6 & 10 \\
\hline $\mathrm{G}_{\text {actual-h }}$ & 0.87 & 0.99 & 0.99 & 1.04 \\
\hline $\mathrm{G}_{\text {actual. } v}$ & 2.41 & 5.74 & 7.22 & 7.78 \\
\hline $\mathrm{G}_{\text {actual }}$ & 2.10 & 5.68 & 7.11 & 8.06 \\
\hline
\end{tabular}

Table 6c. Simulated guide gains for POW3 ( $\mathrm{L}_{\mathrm{lnc}}=8.0 \mathrm{~m}$ with no gap).

\begin{tabular}{|l|c|c|c|c|}
\hline$\lambda$ & 1 & 3 & 6 & 10 \\
\hline $\mathrm{G}_{\text {actual-h }}$ & 0.90 & 1.13 & 1.12 & 1.12 \\
\hline $\mathrm{G}_{\text {actual-v }}$ & 2.41 & 3.60 & 3.74 & 3.75 \\
\hline $\mathrm{G}_{\text {actual }}$ & 2.16 & 4.08 & 4.18 & 4.19 \\
\hline
\end{tabular}


For the case where the guide starts at $8 \mathrm{~m}$ from the moderator, the values from the simulation (Table 6c) agree very well with those from the analytical calculation (Table 5b). However, when the guide starts at $2.5 \mathrm{~m}$ from the moderator the simulation values (Table $6 \mathrm{~b}$ ) fall well below those calculated analytically (Table 5a). These differences can be ascribed to the fact that the additional gains in the $2.5 \mathrm{~m}$ case result entirely from the supermirror guides used in the vertical direction. The simulation used an average reflectivity of 0.95 for the supermirror while the analytical calculation assumed a reflectivity of 1.00. The higher gains are achieved by having several reflections from the supermirror surfaces, in which case the less-than-perfect reflectivity results in significant losses.

Including a gap for a $T_{0}$ chopper reduces the gain from 8.1 to 7.3 at $10 \AA$, with somewhat smaller effects at the shorter wavelengths. Truncation of the guide sides at $4 \mathrm{~m}$ from the sample limits the maximum horizontal divergence to that which would be obtained with natural collimation (sample viewing the entire moderator) so that the guide will not impact the resolution. Under these conditions the sides of the guide provide little or no gain but do allow a smaller beam to be brought out from the biological shield, resulting in shorter chopping times and reduced background.

\subsection{Detectors}

The detectors are oriented vertically with centers at a $2.5 \mathrm{~m}$ radius from the sample. These detectors provide continuous coverage from $\sim 15^{\circ}$ to $\sim 165^{\circ}$ on both sides of the sample. The linear position sensitive detectors are used in the forward and backscattering directions where the detector axes deviate significantly from the Debye-Scherrer cones.

\section{Performance}

\subsection{Resolution}

The parameter of interest for powder diffraction is the inter-plane spacing $d$ given by

$$
\mathrm{d}=\frac{\lambda}{2 \sin \theta}=\frac{3955.4 \mathrm{t}}{2 \mathrm{~L} \sin \theta}
$$

The resolution in this variable is given approximately by

$$
\frac{\delta \mathrm{d}}{\mathrm{d}}=\left\{\left(\frac{\delta \mathrm{t}}{\mathrm{t}}\right)^{2}+\left(\frac{\delta \mathrm{L}}{\mathrm{L}}\right)^{2}+(\cot \theta \delta \theta)^{2}\right\}^{1 / 2}
$$

Table 7 shows the resolution calculated at different scattering angles for this instrument. 
Table 7. Resolution and dynamic range for POW3.

\begin{tabular}{|l|c|c|c|}
\hline \multirow{2}{*}{$2 \theta$} & \multicolumn{3}{|c|}{ Frames 1-4 } \\
\cline { 2 - 4 } & $\delta \mathrm{d} / \mathrm{d}(\mathrm{fwhm})$ & $\mathrm{d}_{\min }(\AA)$ & $\mathrm{d}_{\max }(\AA)$ \\
\hline $160^{\circ}$ & $1.4 \times 10^{-3}$ & 0.09 & 4.1 \\
\hline $90^{\circ}$ & $2.7 \times 10^{-3}$ & 0.13 & 5.7 \\
\hline $30^{\circ}$ & $8.7 \times 10^{-3}$ & 0.35 & 15.6 \\
\hline
\end{tabular}

\subsection{Bandwidth and Dynamic Range}

Running the bandwidth-limiting choppers at $30 \mathrm{~Hz}, 20 \mathrm{~Hz}$, or $15 \mathrm{~Hz}$ allows reasonable operation using one pulse in two, one pulse in three, or one pulse in four, with corresponding maximum wavelength of $4.06 \AA, 6.09 \AA$, or $8.11 \AA$. In these modes, some portions of the wavelength range starting at $2.03 \AA, 4.06 \AA$, and $6.09 \AA$ may be contaminated by the intervening prompt pulses. Figure 2a shows an example of the $15 \mathrm{~Hz}$ operation.

An alternate mode of operation is to run the bandwidth-limiting choppers at $60 \mathrm{~Hz}$, phased to select a wavelength range that falls between various of the prompt pulses. This wavelength range can be in the first frame (before the following pulse), the second frame (one intervening prompt pulse), and so forth. This chopper scheme provides clean operation in the first, second, third, and fourth frames for this instrument, giving access to wavelength ranges of $\sim 0.18$ to $2.03 \AA,-2.08$ to $4.06 \AA, \sim 4.11$ to $6.09 \AA$, and $\sim 6.14$ to $8.11 \AA$, respectively. These choppers cannot handle all potential frame overlap problems when trying to work beyond the fourth frame at $60 \mathrm{~Hz}$. Accessing some higher wavelengths may be possible by reducing the bandwidth-limiting chopper frequency to $30 \mathrm{~Hz}$ or less to eliminate some of the pulses, but this will give, at best, only spotty coverage at wavelengths above $8.11 \AA$.

Table 7 shows the dynamic range at different scattering angles with these wavelength ranges.

\subsection{Data Rates}

Data rate estimates for this instrument will be provided in a later Technical Note.

\section{References}

1. SNS Conceptual Design Report values for decoupled poisoned supercritical hydrogen moderator.

2. K. E. Larsson, U. Dablborg, S. Holmryd, K. Otnes, and R. Stedman, "The Slow Chopper and Time-of-Flight Spectrometer in Theory and Experiment", Arkiv. Fys. 16, 199 (1959).

3. B. Jacrot, "Utilization of Neutron Guide Tubes for Neutron Inelastic Scattering", in Instrumentation for Neutron Inelastic Scattering Research, IAEA,Vienna, pp 233-235, 1970.

4. B. Farnoux, B. Hennion, and J. Fagot, in Neutron Inelastic Scattering (Proc. Symp. Copenhagen, 1968), Vol. 2, IAEA, Vienna, Austria, pp. 353-380. 


\section{Appendix A - Equations used for the chopper calculations}

The following equations were used to calculate the chopper parameters in Tables 2 and 3. These equations were derived under the assumption that the fully-open wavelength range from $\lambda_{\text {co }}$ to $\lambda_{s c}$ is the same for the $T_{0}$ chopper and all bandwidth choppers.

The maximum time-of-flight for neutrons arriving at the detectors in the $\mathrm{N}^{\text {th }}$ frame is

$$
t_{\max -(\mathrm{N})}=\frac{N_{\text {frame }}}{f_{\text {source }}}
$$

The first frame is the period between when the neutrons leave the moderator and the next $T_{0}$ pulse, the second frame is the time between this $T_{0}$ pulse and the following $T_{0}$ pulse, and so on. The maximum incident wavelength on a diffractometer in the $\mathrm{N}^{\text {th }}$ frame is

$$
\lambda_{\text {inc-max }-(\mathrm{N})}=\mathrm{t}_{\max -(\mathrm{N})} \frac{3955.4}{\mathrm{~L}_{\mathrm{d}}}
$$

where $L_{d}$ is the moderator-sample-detector distance. The similar quantity for a crystal-analyzer instrument is

$$
\lambda_{\text {inc- } \max -(\mathrm{N})}=\left(\mathrm{t}_{\max -(\mathrm{N})}-\frac{\lambda_{\mathrm{a}} \mathrm{L}_{\mathrm{sd}}}{3955.4}\right) \frac{3955.4}{\mathrm{~L}_{\mathrm{s}}}
$$

where $L_{s}$ is the moderator-sample distance, $L_{s d}$ the sample-detector distance, and $\lambda_{a}$ is the wavelength selected by the analyzer crystal.

The time it takes a horizontal-axis $\mathrm{T}_{0}$ chopper with axis parallel to the beam (Fig. A1) to go from fully open to fully closed or vice versa is

$$
\Delta \mathrm{t}_{\mathrm{TO}}=\frac{\mathrm{W}_{\mathrm{T} 0}}{\pi \mathrm{D}_{\mathrm{T} 0} \mathrm{f}_{\mathrm{T} 0}}
$$

where $\mathrm{W}_{\mathrm{TO}}$ is the width of the beam at the point where it is being chopped, $\mathrm{D}_{\mathrm{TO}}$ is the diameter of the $T_{0}$ chopper, and $f_{T O}$ is the frequency of rotation of this chopper. The corresponding change in wavelength as the chopper goes from fully open to fully closed is

$$
\Delta \lambda_{\mathrm{TO}}=\frac{3955.4 \Delta \mathrm{t}_{\mathrm{T} 0}}{\mathrm{~L}_{\mathrm{T} 0}}
$$

where $L_{T 0}$ is the distance from the moderator to the $T_{0}$ chopper. 

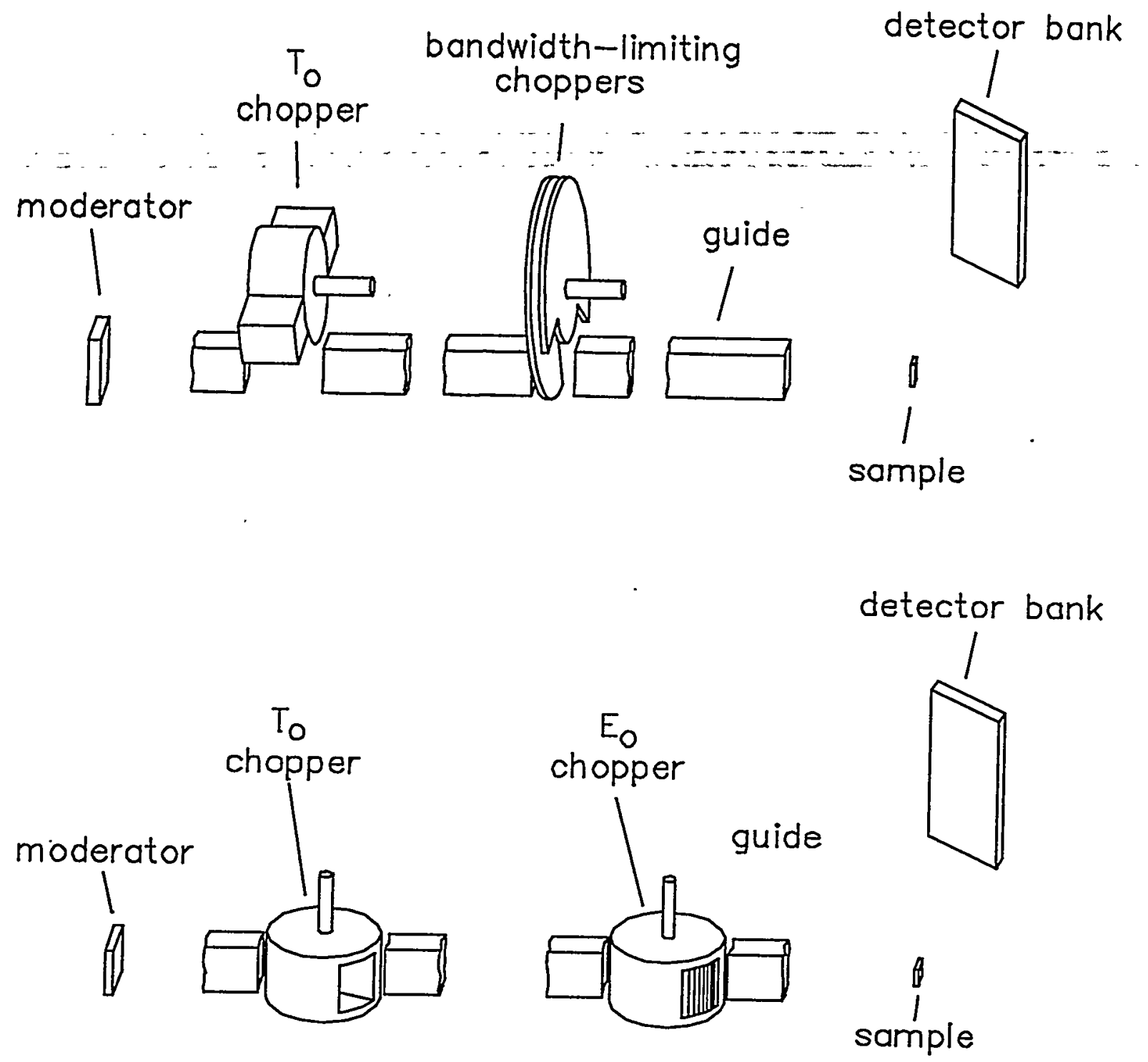

Fig. A1. Schematic view of the use of horizontal-axis $T_{0}$ and bandwidth choppers (upper figure) and of vertical-axis $T_{0}$ and $E_{0}$ choppers (lower figure).

The corresponding quantities for a horizontal-axis bandwidth chopper with axis parallel to the beam (Fig. A1) are

$$
\begin{aligned}
\Delta t_{B W} & =\frac{W_{B W}}{\pi D_{B W} f_{B W}} \\
\Delta \lambda_{B W} & =\frac{3955.4 \Delta t_{B W}}{L_{B W}} .
\end{aligned}
$$


The $T_{0}$ chopper must be closed at the time of each prompt pulse. The wavelength thus fully blocked for the $\mathrm{N}^{\text {th }}$ frame is

$$
\lambda_{c-(\mathrm{N})}=\frac{3955.4 \mathrm{t}_{\max }=(\mathrm{N}-1)}{\mathrm{L}_{\mathrm{T} 0}}
$$

The chopper usually is designed to be fully closed for a short period $\Delta t_{c l}$ centered at $t_{\min -(\mathrm{N}-1)}$, in order to allow for phasing errors and sometimes also to block the entire fast neutron penumbra when it is closed. With these definitions the wavelength at which the chopper starts to open is

$$
\lambda_{\mathrm{so}-(\mathrm{N})}=\lambda_{\mathrm{c}-(\mathrm{N})}+\frac{1}{2} \frac{3955.4 \Delta \mathrm{t}_{\mathrm{cl}}}{\mathrm{L}_{\mathrm{TO}}}
$$

and the wavelength at which it becomes fully open is

$$
\lambda_{\mathrm{co}-(\mathrm{N})}=\lambda_{\mathrm{c}-(\mathrm{N})}+\frac{1}{2} \frac{3955.4 \Delta \mathrm{t}_{\mathrm{cl}}}{\mathrm{L}_{\mathrm{TO}}}+\Delta \lambda_{\mathrm{TO}}
$$

The wavelength at which it again starts to close is

$$
\lambda_{\mathrm{sc}-(\mathrm{N})}=\frac{3955.4 \mathrm{t}_{\max -(\mathrm{N})}}{\mathrm{L}_{\mathrm{T} 0}}-\frac{1}{2} \frac{3955.4 \Delta \mathrm{t}_{\mathrm{cl}}}{\mathrm{L}_{\mathrm{T} 0}}-\Delta \lambda_{\mathrm{T} 0}
$$

and the wavelength at which it finishes closing is

$$
\lambda_{c c-(\mathrm{N})}=\frac{3955.4 \mathrm{t}_{\max -(\mathrm{N})}}{\mathrm{L}_{\mathrm{T} 0}}-\frac{1}{2} \frac{3955.4 \Delta \mathrm{t}_{\mathrm{cl}}}{\mathrm{L}_{\mathrm{T} 0}} .
$$

The corresponding times the $T_{0}$ chopper opens and closes are

$$
\begin{aligned}
& t_{c-(N)}=\frac{\lambda_{c-(N)} L_{T 0}}{3955.4} \\
& t_{s 0-(N)}=\frac{\lambda_{80-(N)} L_{T 0}}{3955.4} \\
& t_{c 0-(N)}=\frac{\lambda_{c 0-(N)} L_{T 0}}{3955.4}
\end{aligned}
$$




$$
\begin{aligned}
& \mathrm{t}_{\mathrm{sc}-(\mathrm{N})}=\frac{\lambda_{\mathrm{sc}-(\mathrm{N})} \mathrm{L}_{\mathrm{TO}}}{3955.4} \\
& \mathrm{t}_{\mathrm{cc}-(\mathrm{N})}=\frac{\lambda_{\mathrm{cc}-(\mathrm{N})} \mathrm{L}_{\mathrm{TO}}}{3955.4^{-}}
\end{aligned}
$$

Note that these are times at the chopper and not time-of-flight to the detectors.

In order to avoid confusion in the data, the bandwidth choppers and the data collection electronics must eliminate all ambiguity as to which frame the neutrons are from. Thus all neutrons from frame $\mathrm{N}-1$, including those coming through a partially closed chopper, must have arrived before any neutrons to be used from frame $\mathrm{N}$ arrive (see Fig. 2). Therefore, there is no point in having the chopper fully open in frame $N$ for wavelengths less than $\lambda_{\text {inc-min-(N) }}$ given by

$$
\lambda_{\text {inc-min-(N) }}=\lambda_{\text {inc-max-(N-1)}}+\Delta \lambda_{\mathrm{BW}}
$$

Thus there is a wavelength range $\Delta \lambda$ in each frame that cannot be used. The associated minimum useful time-of-flight at the detector is

$$
t_{\min -(\mathrm{N})}=\frac{\lambda_{\text {inc-min-(N)}} L_{d}}{3955.4}
$$

Similar to the case for the $T_{0}$ chopper, the opening and closing of the bandwidth limiting choppers can also be related to specific wavelengths. These choppers are typically fully closed for significant periods of time, so four such wavelengths can be defined. These are the wavelength passing through the chopper as it starts to open,

$$
\lambda_{s 0-(\mathrm{N})}=\lambda_{\mathrm{inc- \operatorname {min } - ( \mathrm { N } )}}-\Delta \lambda_{\mathrm{BW}},
$$

the wavelength passing through the chopper as it becomes fully open,

$$
\lambda_{\text {eo-(N) }}=\lambda_{\text {inc-min-(N) }},
$$

the wavelength passing through the chopper as it starts to close,

$$
\lambda_{\mathrm{sc}-(\mathrm{N})}=\lambda_{\text {inc-max-(N)}},
$$

and the wavelength passing through the chopper as it becomes fully closed,

$$
\lambda_{\text {ec-(N) }}=\lambda_{\mathrm{inc- \operatorname {max } - ( \mathrm { N } )}}+\Delta \lambda_{\mathrm{BW}} .
$$

The corresponding times the bandwidth choppers open and close are 


$$
\begin{aligned}
\mathrm{t}_{\mathrm{so}-(\mathrm{N})} & =\frac{\lambda_{\mathrm{BD}-(\mathrm{N})} \mathrm{L}_{\mathrm{BW}}}{3955.4} \\
\mathrm{t}_{\mathrm{co-}(\mathrm{N})} & =\frac{\lambda_{\mathrm{co}-(\mathrm{N})} \mathrm{L}_{\mathrm{BW}}}{3955.4} \\
\mathrm{t}_{\mathrm{sc}-(\mathrm{N})} & =\frac{\lambda_{\mathrm{sc}-(\mathrm{N})} \mathrm{L}_{\mathrm{BW}}}{3955.4} \\
\mathrm{t}_{c c-(\mathrm{N})} & =\frac{\lambda_{\mathrm{cc}-(\mathrm{N})} \mathrm{L}_{\mathrm{BW}}}{3955.4}
\end{aligned}
$$

For the vertical axis $T_{0}$ chopper, the corresponding value for $\Delta t_{\text {to }}$ is given by

$$
\Delta t_{T 0 v}=\frac{W_{T 0}}{2 \pi D_{T 0} f_{T 0}}
$$

and the associated wavelength change while the chopper is opening or closing is

$$
\Delta \lambda_{\text {TOv }}=\frac{3955.4 \Delta \mathrm{t}_{\mathrm{TOV}}}{\mathrm{L}_{\mathrm{TO}}}
$$

The factor of 2 arises because both sides of the chopper are moving into or out of the beam at the same time, so each edge must move through only half the beam in going from completely open to completely closed or vice versa. Such a $T_{0}$ chopper is usually operated at a high rotational speed and is only open for a short period of time twice per revolution. The chopper is phased to be open at time $t_{\lambda}$ to transmit the desired wavelength $\lambda$.

$$
t_{\lambda}=\frac{L_{T 0} \lambda}{3955.4} .
$$

The chopper usually is designed to be fully open for a short period $\Delta t_{\text {opv }}$ centered at $t_{\lambda}$, in order to allow for phasing errors and to transmit the full width of the pulse from the moderator. With these definitions the times the $T_{0}$ chopper opens and closes are

$$
\begin{gathered}
\mathrm{t}_{\mathrm{sov}}=\mathrm{t}_{\lambda}-\frac{\Delta \mathrm{t}_{\mathrm{opv}}}{2}-\Delta \mathrm{t}_{\mathrm{TOv}} \\
\mathrm{t}_{\mathrm{cov}}=\mathrm{t}_{\lambda}-\frac{\Delta \mathrm{t}_{\mathrm{opv}}}{2}
\end{gathered}
$$




$$
\begin{gathered}
t_{s c v}=t_{\lambda}+\frac{\Delta t_{o p v}}{2} \\
t_{c c v}=t_{\lambda}+\frac{\Delta t_{\text {opy }}}{2}+\Delta t_{T O v}
\end{gathered}
$$

Note that these are times at the chopper and not time-of-flight to the detectors.

The vertical axis $E_{0}$ chopper is generally a Fermi chopper with a slit package passing through the chopper body normal to the axis of rotation, as shown in Figure A1. This slit package contains multiple absorbing vanes, usually curved, which serve to transmit only a very narrow burst of neutrons. The chopper is phased so that this burst is centered at the wavelength of interest. A description of the burst width and transmission of such a chopper is beyond the scope of this note (see however Reference 2). 


\section{Appendix B - Equations used for the guide calculations}

The guide gain is the ratio of the flux on sample with the guide to that with no guide. The gain of a guide depends on whether the guide is fully illuminated by the moderator, and also on whether the sample is fully illuminated by the guide. The following equations can be used to estimate the ideal guide gain $\mathrm{G}_{\mathrm{ideal}-\mathrm{h}}$ for a fully illuminated horizontal non-converging guide, and the actual guide gain $\mathrm{G}_{\text {actual-h }}$ when the effects of less than full illumination of the guide or of the sample are considered.

The effective critical angle as a function of the wavelength $\lambda$ for reflection from the side walls of a guide with a supermirror having $\mathrm{m}_{\mathrm{h}}$ times the critical angle for natural nickel is

$$
\theta_{\text {eff-h }}=0.0017 \mathrm{~m}_{\mathrm{h}} \lambda
$$

If the spacing between the guide walls is $\mathrm{g}_{h}$ and the moderator horizontal dimension is $\mathrm{M}_{\mathrm{h}}$, then the maximum moderator-guide distance for full guide illumination is

$$
L_{\text {inc-full-h }}=\frac{M_{h}-g_{h}}{2 \theta_{\text {eff-h }}}
$$

The ideal horizontal gain of the guide must be multiplied by a factor $F_{\text {inch }}$ to account for the possibility that the guide is not fully illuminated by the moderator.

$$
\begin{array}{cl}
F_{\text {inc-h }}=1 & L_{\text {inc-h }} \theta_{\text {eff }-h}<\frac{M_{h}-g_{h}}{2} \\
F_{\text {inc-h }}=\frac{M_{h}+g_{h}-L_{\text {inc-h }} \theta_{\text {eff-h }}}{2 g_{h}}-\frac{\left(M_{h}-g_{h}\right)^{2}}{8 L_{\text {inc-h }-\mathrm{eff}-h} g_{h}} & \frac{M_{h}-g_{h}}{2}<L_{\text {inc-h }} \theta_{\text {eff-h }}<\frac{M_{h}+g_{h}}{2} \\
F_{\text {inc-h }}=\frac{M_{h}}{2 L_{\text {inc-h }} \theta_{\text {eff-h }}} & L_{\text {inc-h }} \theta_{\text {eff-h }}>\frac{M_{h}+g_{h}}{2}
\end{array}
$$

Similarly, the guide may not fully illuminate the sample of width $S_{h}$, so another correction factor $F_{\text {exit- }}$ is needed. This correction factor must also take into account whether the guide itself is fully illuminated, in order to avoid double counting of the gain reductions. This is done approximately in the following equations.

$$
\mathrm{F}_{\text {exit-h }}=1 \quad \mathrm{~L}_{\text {exit-h }} \mathrm{F}_{\text {inc-h }} \theta_{\text {eff-h }}<\frac{g_{h}-S_{h}}{2}
$$




$$
\begin{gathered}
F_{\text {exil-h }}=\frac{g_{h}+S_{h}-L_{\text {exit-h }} F_{\text {inc-h }} \theta_{\text {eff-h }}}{2 S_{h}}-\frac{\left(g_{h}-S_{h}\right)^{2}}{8 L_{\text {exit-h }} F_{\text {inc-h }} \theta_{\text {eff }-h} S_{h}} \\
\quad \frac{g_{h}-S_{h}}{2}<L_{\text {exit-h }} F_{\text {inc-h }} \theta_{\text {eff-h }}<\frac{g_{h}+S_{h}}{2} \\
F_{\text {exit-h }}=\frac{g_{h}}{2 L_{\text {exit-h }} F_{\text {inc-h }} \theta_{\text {eff-h }}} \quad L_{\text {exit-h }} F_{\text {inc-h }} \theta_{\text {eff-h }}>\frac{g_{h}+S_{h}}{2}
\end{gathered}
$$

The ideal guide gain in the horizontal direction is

$$
\begin{array}{ll}
G_{\text {ideal }-h}=\frac{g_{h}-L \theta_{\text {eff-h }}}{M_{h}} \frac{L}{L-L_{\text {inc-h }}}+\frac{2\left(L \theta_{\text {eff-h }}\right)^{2}}{g_{h} M_{h}} & \left(L-L_{\text {inc-h }}\right) \theta_{\text {eff }-h}<\frac{g_{h}}{2} \\
G_{\text {ideal-h }}=\frac{2 \theta_{\text {eff-h }} L}{M_{h}} & \left(L-L_{\text {inc-h }}\right) \theta_{\text {eff-h }}>\frac{g_{h}}{2}
\end{array}
$$

where $L$ is the source-sample distance, and the actual gain in the horizontal direction is

$$
G_{\text {actual-h }}=F_{\text {inc-h }} F_{\text {exit-h }} G_{\text {ideal }-h}
$$

For short wavelengths the gain can be less than 1 if the guide actually obscures part of the moderator.

The corresponding equations for a vertical guide are obtained by replacing $h$ by $v$ in the subscripts to these equations. The total guide gain is the product of the corresponding horizontal and vertical gains.

$$
\begin{aligned}
G_{\text {ideal }} & =G_{\text {ideal-h }} G_{\text {ideal-v }} \\
G_{\text {actual }} & =G_{\text {actual-h }} G_{\text {actual-v }}
\end{aligned}
$$

If the guide is curved in the horizontal plane to remove the fast and epithermal background from the beam, the line-of-sight length $L_{\text {sight }}$ for this guide is given by

$$
\mathrm{L}_{\text {sight }}=\sqrt{8 \mathrm{gR}}
$$

where $R$ is the radius of curvature. The actual guide length $L$ should be about 1.1-1.2 $\mathrm{L}_{\text {sight }}$ to give the best background reduction. ${ }^{3}$ The characteristic wavelength $\lambda *$ for this guide is given by 


$$
0.0017 \mathrm{~m}_{\mathrm{h}} \lambda *=\sqrt{\frac{2 \mathrm{~g}}{\mathrm{R}}}
$$

In this case the one-dimensional guide gain calculated for the straight guide must be multiplied by a transmission factor $T$ given by:

$$
\begin{array}{cc}
\mathrm{T}=\frac{2}{3} \mathrm{~K}^{2} & \mathrm{~K} \leq 1 \\
\mathrm{~T}=\frac{2}{3} \mathrm{~K}^{2}\left\{1-\left[1-\frac{1}{\mathrm{~K}^{2}}\right]^{3 / 2}\right\} & \mathrm{K}>1
\end{array}
$$

where

$$
\mathrm{K}=\frac{\lambda}{\lambda *}
$$

